\title{
Effect of Convection Currents on the Distribution of Striae in Pots of Optical Glass
}

\author{
By Conrad A. Faick, Arthur E. Williams, and Gerald F. Rynders
}

\begin{abstract}
The striae distribution in pots of optical glass was studied and the role of convection currents in causing this distribution established. Tracing the convection currents and studying the effect of various cooling techniques on such currents was achieved through the introduction of copper oxide into the melts on their removal from the furnace.
\end{abstract}

\section{Introduction}

In all optical glass manufacture a large proportion of the glass in a pot is rejected for defects of one kind or another. Striae, or streaks of different composition within the glass mass, constitute one of the major defects. They are present in all pots of optical glass. However, the amount of glass rejected because of striae is dependent entirely on its distribution in the glass. Fenner [1], ${ }^{1}$ Roberts [2], and Wright [3] state that convection currents, set in motion after a pot of glass is removed from the furnace, are largely responsible for the amount of glass rejected for striae.

Other factors, such as pot solution [4], volatilization, and effectiveness of stirring probably determine the amount of striae present, but their distribution is due primarily to convection currents. If the stirring is adequate to keep ahead of striae formation, and the pot of glass at the time of removal from the furnace is free from striae, except possibly for a thin layer in contact with the pot and on the surface of the glass, the problem of striae control becomes one of reduction or control of convection currents.

This paper deals with a study of the striae bands found in optical glass, the role of convection currents in striae distribution, and variations of cooling techniques used to reduce or control convection currents.

\footnotetext{
1 Figures in brackets indicate the literature references at the end of this paper.
}

\section{Location and Shape of Striae Bands}

It has been the practice at the National Bureau of Standards [5] to tank inspect all optical glass prior to molding it into lens blanks. This inspection of a large number of melts revealed the tendency for striae to be concentrated in certain portions of the melt and to follow a characteristic pattern. For closer study of the striae distribution, samples were selected from definite portions of the melt. Usually, 15 samples were inspected for each melt, representing the center and four quadrants at three different levels, i. e., top, middle, and bottom.

From observation of the striae in the samples, sketches were often made that showed the pattern of the striae and permitted an estimate of the amount present. The sketches shown in figure 1 illustrate the position of the samples chosen and a typical striae pattern. The characteristic of the striae, as revealed by these studies, was a heavy vertical band, originating at the bottom of the pot, going up the center, then spreading across the top and going down the sides. Sometimes this heavy band spread out at the top like branches on a tree; but frequently almost all of it deviated to one side, probably because unsymmetrical cooling caused a migration in one direction. The distance of the striae from the top, sides, and bottom was measured on the selected samples and found to vary between $1 / 2$ and 4 in., the average distance being $1 \frac{1}{2}$ in. 
The characteristic striae pattern usually found in a pot of optical glass is illustrated by a few selected samples, which were photographed [6] through the windows of the immersion tank of the inspection apparatus. These are shown in figures 2 to 7 , inclusive.

Figure 2 shows the bands down the side of the pot and a loop of striae, probably representing the end of the center band, brought up into the glass by convection currents. Figure 3 shows a heavy band of striae curving around the lower corner of the pot; figure 4 shows the heavy central vertical band, which is believed to be the origin of most of the striae in the glass. Figure 5 shows the heavy vertical band curving toward the side near the surface. Also, there is shown a band of striae parallel to the surface that does not appear to be related to the former. Figure 6, the top edge, shows the end of the heavy vertical band curving downward after having moved across the top of the pot. It also shows a heavy band very close to the pot wall, which may be the source of the horizontal layer (A) shown in figure 5 .

Figure 7 shows the striae in a sample from the top left side of a melt, and a cloud of "seeds" associated with it. ${ }^{2}$

\section{Cooling Procedure}

Since the magnitude of the convection currents depends largely on the method of cooling a pot of glass after removal from the furnace [2], a brief description of the cooling technique will be given before describing the experiments made to trace the convection currents.

After a pot of glass is removed from the furnace, an insulated can is provided to cool the melt to room temperature. This can consists of a sheet metal cylinder lined with $4 \frac{1}{2} \mathrm{in}$. of insulating brick, and a lid with 9 in. of insulation. A base-metal thermocouple is in the lid. A triangular suspension is attached to the outer shell and the whole assembly placed over the pot by means of an overhead hoist.

The can is suspended over the pot, at a height determined largely by experience, and allowed to hang in this position for several hours, then lowered to cover the pot. The time of lowering the

\footnotetext{
2 Occasionally a melt was produced in which a cloud of seeds formed during the last few minutes of stirring; at times it migrated from the center of the pot toward the edge and on subsequent inspection of the glass was found to occupy the same region as the main striae band.
}

can is determined by the temperature indicated by the thermocouple in the lid. This temperature is purely an arbitrary value, but is usually somewhere near the critical temperature of the glass as shown by its expansion curve. Variations in the height at which the can is suspended and the temperature at which it is lowered are the means of controlling the type of fracture produced. Figure 8 shows a cooling can in its position over a pot of glass.

\section{Study of Convection Currents}

\section{Temperature Distribution in a Pot of Glass}

Regular production borosilicate melts, 517/645, containing approximately 1,000 lb of glass, were used for the study of convection currents. The first melt of the series was used to determine the time-temperature distribution in the glass during the cooling down period after removal from the furnace. Following the regular production schedule [5], the melt was transferred from the furnace at a temperature of $1,025^{\circ} \mathrm{C}$ to piers beneath the suspended cooling can. After placing 16 basemetal thermocouples in the melt, the can was lowered to the position shown in figure 8 and a blower placed beneath the pot. When the temperature indicated by the thermocouple in the lid reached $575^{\circ} \mathrm{C}$, the can was completely lowered.

These thermocouples were connected to a 16 point strip-chart recorder and a continuous timetemperature record obtained. Figure 9 shows the locations of the thermocouples after the pot of glass was broken open for inspection. Couples $17,18,19$, and 20 were intended to go down the center of the pot, but the support broke at the time of immersion, allowing them to deviate to one side. It was assumed that the temperature distribution would be svmmetrical about the center line of the pot. A comparison of the temperature shown by the deviated couples with the adjacent column of couples tends to substantiate this assumption.

Assuming symmetrical temperature distribution, a series of drawings were made showing the probable isotherms at various times during cooling of the melt. From the time-temperature curves of figure 10 and the probable isothermal sketches of figure 11, the temperature changes taking place during the first few hours of cooling are readily apparent. 
At the time of removal from the furnace the central and lower portions of the melt were considerably hotter than the top, but horizontal gradients were relatively slight. One-half hour later the top edges had become considerably colder than even the top center. As cooling continued, the top edges and sides cooled more rapidly than the bulk of the glass, but nearly $2 \mathrm{hr}$ elapsed before the bottom showed any appreciable drop in temperature below the center portion.

When the cooling can was lowered to the floor, there was a definite change in the rate of cooling of the various portions of the melt (see fig. 10). About $3 \frac{1}{2} \mathrm{hr}$ later, the top center (curve T. C. 20) had become the hottest portion. The rapid cooling of the top edges during the early stages was regarded as the cause of the observed convection currents due to changes in density.

\section{Tracing Convection Currents}

In order to trace the motion of the glass in a cooling pot, a coloring agent was introduced into the melt just after removal from the furnace. Copper oxide, wrapped with copper screen to form balls about $3 / 4 \mathrm{in}$. in diameter, was used to provide the color. Two of these balls, each weighted with a steel ball in the center, were permitted to sink to the bottom of the pot, and two were suspended from a bar across the top of the pot, so that they would hang about $4 \mathrm{in}$. below the surface of the glass. The balls were positioned in the melt so that there would be one ball in each quadrant, approximately half way between the center and edge of the pot.

The copper oxide was readily dissolved by the glass, giving a dark blue or black color. The colored streamers formed by the glass flowing past the copper oxide balls provided the means for determining the direction and magnitude of the convection currents.

Copper oxide balls were placed in 13 melts, each of which had a somewhat different cooling treatment either during the last hours of melting or just after their removal from the furnace and before placing them under the cooling can. Beginning with the second melt, the cooling can was provided with windows so that the migration of the colored streamers could be observed. The final positions of these streamers were traced after the pot of glass was cold and opened for inspection.
The various cooling treatments and the results are discussed in the following paragraphs in the order in which they were made.

Melt 1. Exit temperature $1,025^{\circ} C .^{3}$ The only observation made on this melt was just before lowering the cooling can to the floor. The colored streamer from ball D (see fig. 12) was found to have gone down the sides of the pot, across the bottom and up the center. Those from A and B had traveled up the center, across the top, down the sides and then curved upward again. One streamer had formed a definite loop, such as shown in figure 12. This loop was formed by the flow of glass crossing and displacing the colored streak left by the copper oxide ball sinking to the bottom of the pot. (Observations on subsequent melts reveal the formation of this characteristic loop).

Melt 2. Exit temperature $1,0 \% 5^{\circ} \mathrm{C}$. The copper oxide balls were introduced immediately on removal of the melt from the furnace. Observation through the cooling can windows indicated that by the time the pot was placed on the cooling piers the balls that were to sink had already reached the bottom, leaving dark streaks behind them. The color from the suspended balls had gone a considerable distance, but had gone toward the center of the pot, then down. About $10 \mathrm{~min}$ later, the directions appeared to have reversed; the original colored streaks had come back up the center, leaving a blotch of color on top, which was moving toward the sides. Then the streaks were observed to go down the sides and up the center, across the top and down the sides again. A slight clockwise motion around the pot was evident, causing the colored streaks to form spirals rather than plane loops. The amount of travel and twisting of the colored streamers soon made it impossible to follow them, but they appeared to make three or more loops. The appearance of the streamers, just before lowering the cooling can, is shown in figure 13. When the glass was opened for inspection, only the more prominent streaks (fig. 14) could be followed, but not too well. The photograph, figure 15 , of both halves of the melt when cold, shows clearly the excessive movement that occurred.

Melt 3. Exit temperature $1,025^{\circ} \mathrm{C}$; water-cooled rod in center of pot. A water-cooled rod was placed

${ }^{3}$ Exit temperature is the temperature at which the melt was removed from the furnace. Unless otherwise stated, the temperatures given here are those indicated by an optical pyrometer sighted on the surface of the melt through the stirring rod opening in the door of the melting surface. 
in the center of this melt after removal from the furnace. Observation of the colored streaks indicated that the movement of the convection currents was slightly less than in other melts removed from the furnace at $1,025^{\circ} \mathrm{C}$, and the direction of travel was reversed. The streaks, as located in the cold glass, are shown in figure 16 . Due to somewhat unsymmetrical cooling, the streamer from A appears to bend back on itself. However, it is practically the same as that from $\mathrm{B}$ but is directed along the pot wall rather than toward the center. Color from the suspended balls $\mathrm{C}$ and $\mathrm{D}$ moved very little.

Melt 4. Exit temperature $1,025^{\circ} \mathrm{C}$; water-cooled. Immediately after removal from the furnace the copper oxide balls were placed in the pot, the melt then placed on a cooling rack and sprayed with water ${ }^{4}$ on the bottom and on the sides up to the pot knuckle, or shoulder. The water spray was applied for $30 \mathrm{~min}$. and the pot then transferred to the regular cooling piers. The balls $\mathrm{A}$ and $\mathrm{B}$ were somewhat slow in sinking to the bottom, due to the chilled surface of the glass, which was not covered during the spraying period. On sinking, these balls left streaks of color behind which, after a few minutes, curved inward at a position about two-thirds of the way down. After about 45 min. these curved portions had formed loops that had progressed toward the center of the pot and upward. The formation of these loops gives the effect of double streamers. They are caused by the flow of glass from near the pot wall crossing the color paths left by the balls in sinking. The formation of these loops is illustrated by the sketches in figure 17 . Figure 18 shows the fina! position of the colored streamers in melt 4 .

Melt 5. Exit temperature $1,025^{\circ} \mathrm{C}$; water-cooled, with lid. This melt was covered immediately on removal from the furnace with a lid made of insulating brick $4 \frac{1}{2} \mathrm{in}$. thick to prevent rapid chilling of the top surface of the glass while the melt was being water cooled. Due to the lid, observations were necessarily delayed until after the water cooling was finished. At the time of the first observation, the loops in tne color streamers had reached the top of the pot and gave the appearance of being double streamers originating from the submerged balls. These streamers did not rise directly in the

\footnotetext{
4 An ordinary shower head, inverted, provided the spray for the bottom of the pot. A tubular ring perforated with a large number of small holes, suitably directed, provided the spray for the sides of the pot.
}

center of the pot, but slightly to one side, and those portions near the surface were also displaced, indicating unsymmetrical cooling.

The paths of the observed currents are shown in figure 19. The dotted portions shown in the top views represent those portions of the streamers across the bottom of the pot. The final positions of the colored streamers are shown in figure 20.

Melt 6. Exit temperature 1,025 $\mathrm{C}$; air-cooled, with lid. The lid was placed on this melt for the first half hour of cooling in the belief that it would be more effective than the suspended can in keeping the top surface from chilling.

After removal of the lid it was noted that the color from the suspended balls (C and D) had traveled across the top, down the sides, across the bottom, and up the center in much the same manner as in melt 1 . The balls $A$ and $B$ sank in a straight line to the bottom of the pot, leaving colored streaks behind. A and B were placed too close to the edge, so that the flow of glass did not displace the streamers as much as in previous melts. As judged subsequently by observations through the top of the insulated can, the positions of these bands at different times were approximately as shown in figure 21. The positions in the cold pot are shown in figure 22 .

Melt $\%$. Exit temperature $\left(975^{\circ} C\right)$; regular cooling, as in melt 1. This melt was cooled in the furnace, with stirring, to $975^{\circ} \mathrm{C}$. The copper oxide balls were placed in the melt. But those that were supposed to sink stayed on the surface, and the suspended balls remained stationary. No color streaks developed from any of them. At this temperature the glass was sufficiently viscous that the motion, if any, could not be observed by the use of the copper-oxide balls. The melt was full of striae, which appeared to have been dragged from the pot walls by the action of the stirrer.

Melt 8. Exit temperature $1,050^{\circ} \mathrm{C}$; remained in furnace $2 \mathrm{hr}$ at $1,050^{\circ} \mathrm{C}$. The holding period at $1,050^{\circ} \mathrm{C}$ was intended to establish uniform temperature throughout the melt before removal from the furnace. This was based on the previous temperature probe and would be about equivalent to the normal exit temperature of $1,025^{\circ} \mathrm{C}$ without the holding period. The motion as shown by $\mathrm{A}$ and $\mathrm{B}$, figure 23 , was practically the same as in melts removed at $1,025^{\circ}$ C. However, colors developed at $\mathrm{C}$ and $\mathrm{D}$ moved very little due to the chilling of the surface. 
Melt 9. Held 2 hr at $1,050^{\circ} \mathrm{C}$; surface raised to $1,075^{\circ} C$ within $15 \mathrm{~min}$ before removal. The raising of the surface temperature at the end of the holding period at $1,050^{\circ} \mathrm{C}$ was effective in reducing the chilling of the top surface immediately after removal from the furnace. The observed movement of the glass was essentially the same as in the previous melt, except that the color from $\mathrm{C}$ and $\mathrm{D}$ moved farther. The rapid raising of the temperature to $1,075^{\circ} \mathrm{C}$ had very little effect on the magnitude of the convection currents. The cooling was very unsymmetrical, due mostly to an improperly hung can, so that the streamers went down one side of the pot and up the opposite side, rather than rising at the center. The appearance of the streamers as viewed from the top is shown in figure 24. Also in figure 24 are shown the final positions of the colors in the cold pot.

Melt 10. Held $1 \frac{1}{2}$ hr at $1,000^{\circ} \mathrm{C}$ surface raised to $1,025^{\circ} C$ in 15 min before removal. As may be seen from figure 25 , the movement of the glass due to convection currents was considerably less than in melts removed from the furnace at $1,025^{\circ} \mathrm{C}$.

The melt had considerable striae, which appeared to have been dragged from the pot wall by the action of the stirrer.

Melt 11. Exit temperature $950^{\circ} \mathrm{C}$; stirring stopped and rod removed at $1,025^{\circ} \mathrm{C}$. The stirring of this melt was discontinued at $1,025^{\circ} \mathrm{C}$, and the melt cooled in the furnace to $950^{\circ} \mathrm{C}$. The one copper-oxide ball used was placed in the glass along the right side of the pot as viewed from the front of the furnace, as soon as the stirring rod was removed at $1,025^{\circ} \mathrm{C}$.

On removing the melt from the furnace, it was found that the color from the copper-oxide ball had migrated toward the front of the pot in a spiral form. The amount of travel was not great, considering that $1 \frac{1}{2} \mathrm{hr}$ had elapsed since the end of the stirring. However, the spiral path taken by the streamer shows that some convection currents were present: As viewed from the top, the colored tracer appeared as shown in figure 26. No motion was observed after the melt was removed from the furnace.

Melt 12. Exit temperature $950^{\circ} \mathrm{C}$; stirring stopped at $1,050^{\circ} \mathrm{C}$; cooling ports in back of furnace. This melt was similar to melt 11 , except for additional cooling of the bottom of the pot provided by openings in the back of the furnace. ${ }^{5}$ Stirring was stopped at $1,050^{\circ} \mathrm{C}$, and a copper oxide ball was placed in the melt, at the front edge of the pot, when the temperature reached $1,025^{\circ}$ C. One and one-half hours later, when the melt was removed from the furnace, the colored tracer appeared to have made three-fourths of a loop. The color progressed from the copper-oxide ball across the bottom of the pot, rising near the far side, then across the top toward the front of the pot. A separate streak, caused by oxide left behind as the ball sank, was also visible. This streak was not connected to the main tracer, but gave the appearance of completing the loop. Only a very slight movement was observed after the melt was removed from the furnace. This was shown by a slight migration of the top portion of the streak toward the side of the pot. The positions of the colored streaks in the cold pot were as shown in figure 27.

Melt 13. Exit temperature $1,050^{\circ} \mathrm{C}$; cooling ports in back wall of furnace opened. Melt 13 was cooled with the back wall ports open and removed at $1,050^{\circ} \mathrm{C}$. The movement of the glass was such that in $40 \mathrm{~min}$ the color streaks had made a complete turn, and a half hour later had made the second revolution. They were soon too difficult to follow. Inspection of the cold pot showed the main streamer from ball $D$ to have made $2 \frac{1}{2}$ turns, and was accompanied by a few secondary streamers caused by disintegration of the copper oxide ball. The streamers from the other balls were too confused to trace properly. The position of the main streamer from ball D only is shown in figure 28.

\section{Discussion}

The introduction of color into melts of optical glass has provided a means of tracing convection currents in the glass during the cooling process. The positions taken by the colored tracers have been found to be similar to, and frequently identical to, the positions occupied by the main striae bands. This correspondence between the observed paths of the colored tracers and the striae bands shows that the convection currents are responsible for the striae distribution. The source of these striae appears to be the glass next to the

5 These openings were 8 in. by 8 in., spaced $3 \mathrm{ft}$. apart and about level with the bottom of the pot. 
walls and bottom of the pot, with the greater amount originating from the bottom of the pot where the stirring is least effective (see fig. 4).

The top horizontal band $A$ in figure 5, which seems to be unrelated to the main striae bands, can also be accounted for by convection currents. There is frequently a movement of the surface glass (melt 2) toward the center of the pot immediately on removal from the furnace; this movement reverses direction when the melt is placed beneath the cooling can. The early motion toward the center could carry glass of different composition from the pot walls and spread it across the top of the melt near the surface where it would be frozen in before the direction of motion was reversed. The heavy band $B$ in figure 6 shows a distinct loop, which could also be explained by this reversal of direction.

The various procedures tried for control of convection currents were only modifications of the standard cooling procedure. Of the various modifications tried, the lowering of the exit temperature was by far the most effective. However, this procedure could be carried out only to a limited extent. When the exit temperature was reduced below $1,025^{\circ} \mathrm{C}$ (melts 7 and 10), striae were dragged into the glass from the pot walls by action of the stirrer. ${ }^{6}$

In regular production, melts of borosilicate glass were removed from the furnace at $1,050^{\circ} \mathrm{C}$ whenever the cooling ports in the back wall of the furnace were used to increase the cooling of the bottom portion of the pots. It was found, however, that these ports were not effective for the purpose intended, and that the higher exit temperature tended to increase the convection currents (see melt 13).

The procedure of cooling the glass in the furnace after discontinuing the stirring reduced the convection currents, but some striae were still evident and appeared to be deeper in the glass. This procedure may be more effective if the stirring could be carried to a temperature well below $1,025^{\circ} \mathrm{C}$.

\footnotetext{
${ }^{6}$ Further reduction of the exit temperature may be possible by the use of a slower speed than that now available, namely. 6 rom.
}

The use of the water-cooled rod in the center of the melt provided too much local cooling and reversed the direction of the convection currents. Although the amount of motion was reduced, the heavy bands of striae were directed downward approximately half way between the center and the walls of the pot, resulting in a more than the usual loss of glass.

Water-cooling the outside of the pot for $1 / 2 \mathrm{hr}$ had practically no effect on the magnitude of the convection currents. The use of the insulating lid only served to direct the striae closer to the pot walls and the surface of the glass.

It was found that the paths of the colored streamers, and consequently the striae layers, depend to a great extent on the symmetry of cooling. To avoid excessive loss of glass from striae, considerable care must be taken to assure that the cooling can is properly placed and the melt allowed to cool symmetrically.

The loss of glass due to the introduction of color was not significant, unless the motion of the glass during cooling was excessive. The colored streaks follow paths taken by the striae and are located in the portions of the melt that would normally be discarded on account of striae.

\section{Conclusion}

The striae distribution in pots of borosilicate $517 / 645$ optical glass was determined and the role of convection currents in causing this distribution established.

Of the various modifications of the cooling procedure employed, that of lowering the exit temperature formerly used, namely $1,075^{\circ} \mathrm{C}$, about $50 \mathrm{deg} \mathrm{C}$ was found to be the most effective in reducing convection currents. Stirring could not be continued much below $1,025^{\circ} \mathrm{C}$, as striae from the pot walls would be dragged into the melt.

The use of copper oxide balls, introduced into the melt after removal from the furnace, proved to be satisfactory for tracing convection currents, and thereby judging the efficacy of the cooling technique employed. 

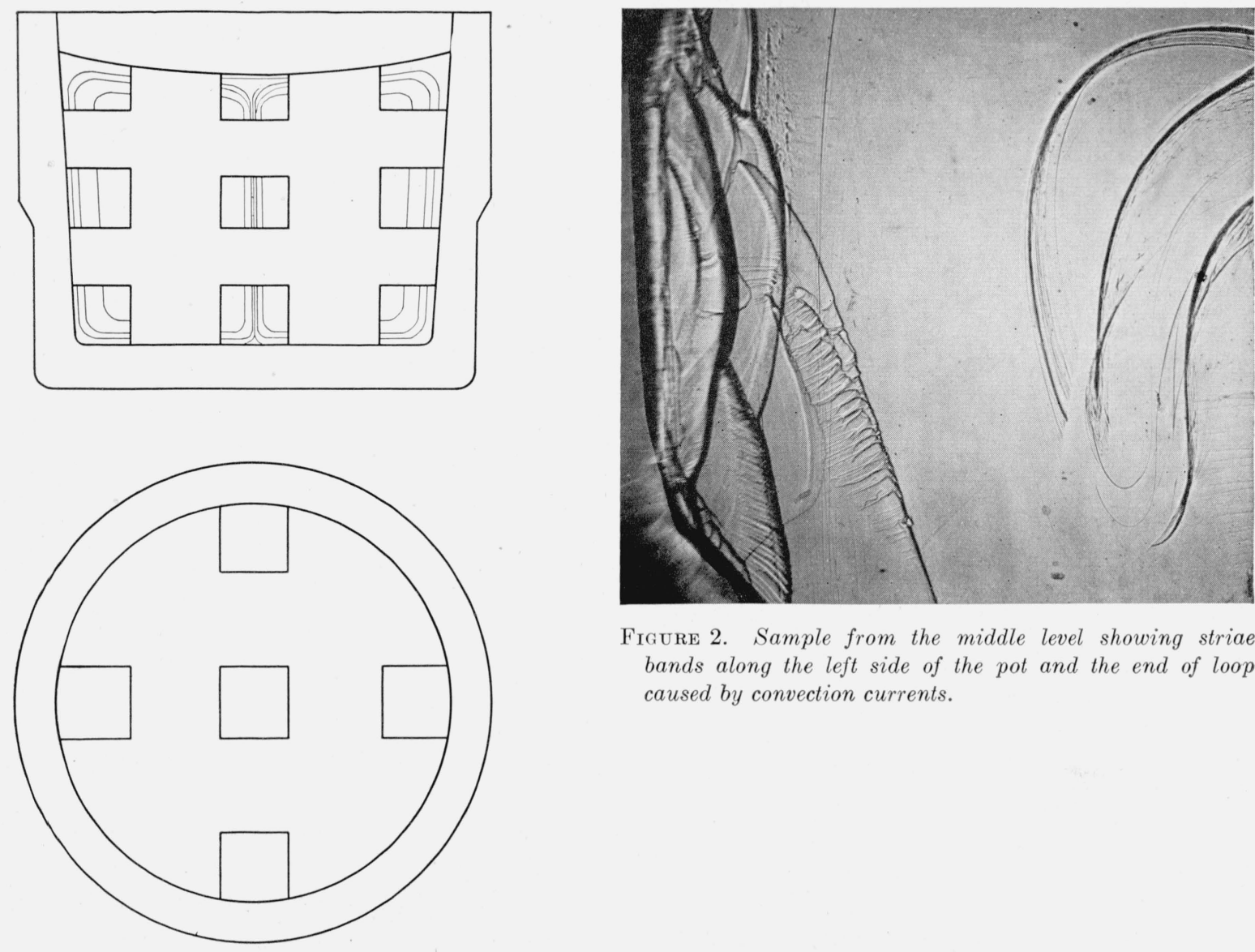

Figure 2. Sample from the middle level showing striae bands along the left side of the pot and the end of loop caused by convection currents.

Figure 1. Diagrams showing the location of the 15 samples chosen for inspection and the approximate location of the main striae bands.

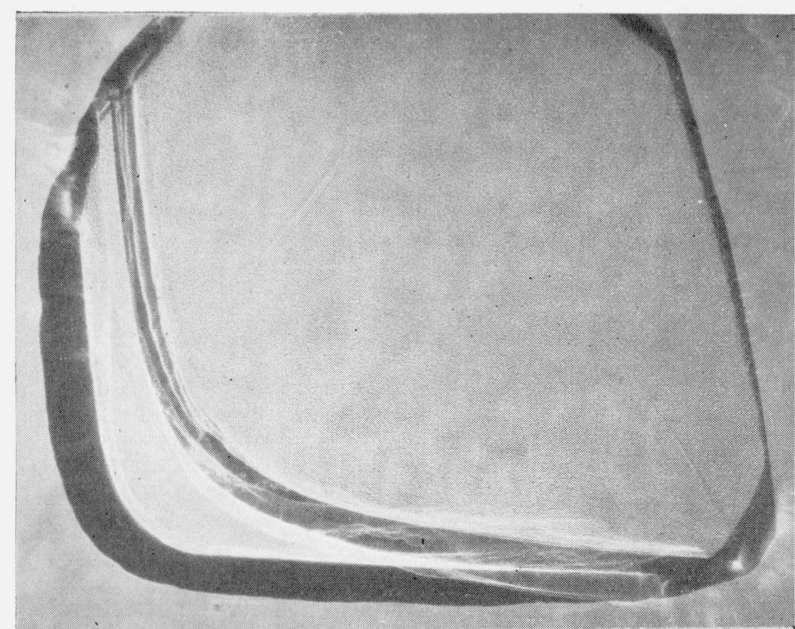

Figure 3. Heavy striae band curving around lower left corner of pot.

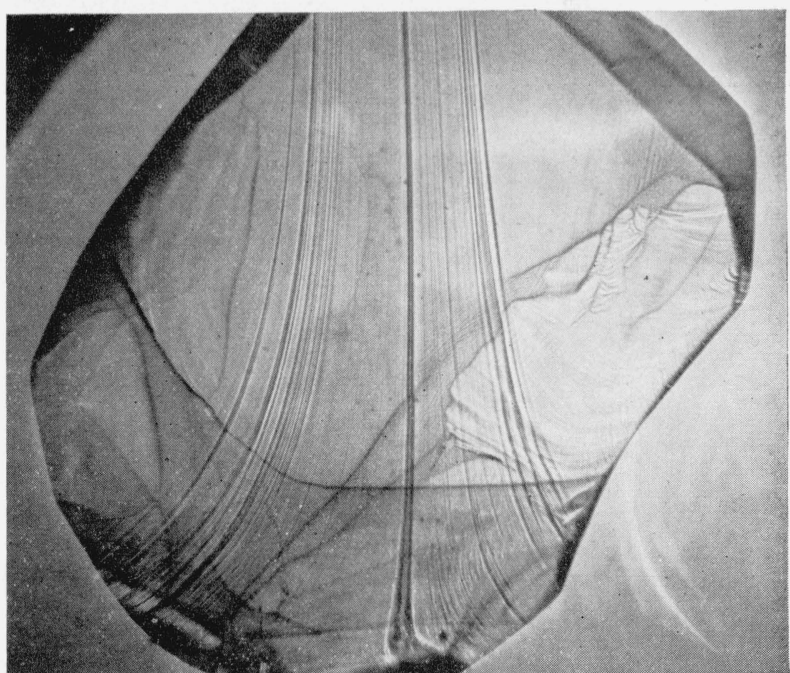

FIGURE 4. Sample from bottom center of a melt showing the origin of the heavy vertical striae band. 


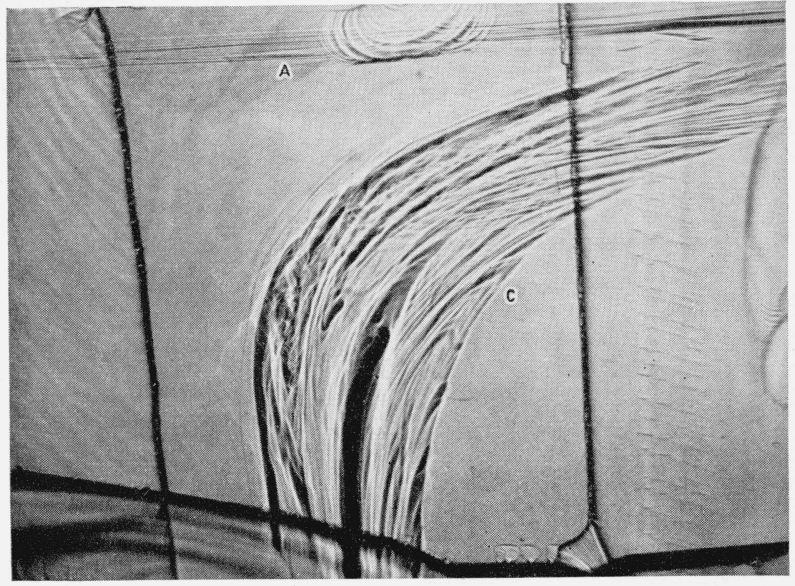

Figure 5. Sample from top center of a melt showing the horizontal surface striae band $(A)$, and the curving of the heavy vertical band $(C)$ toward the right side of the pot.

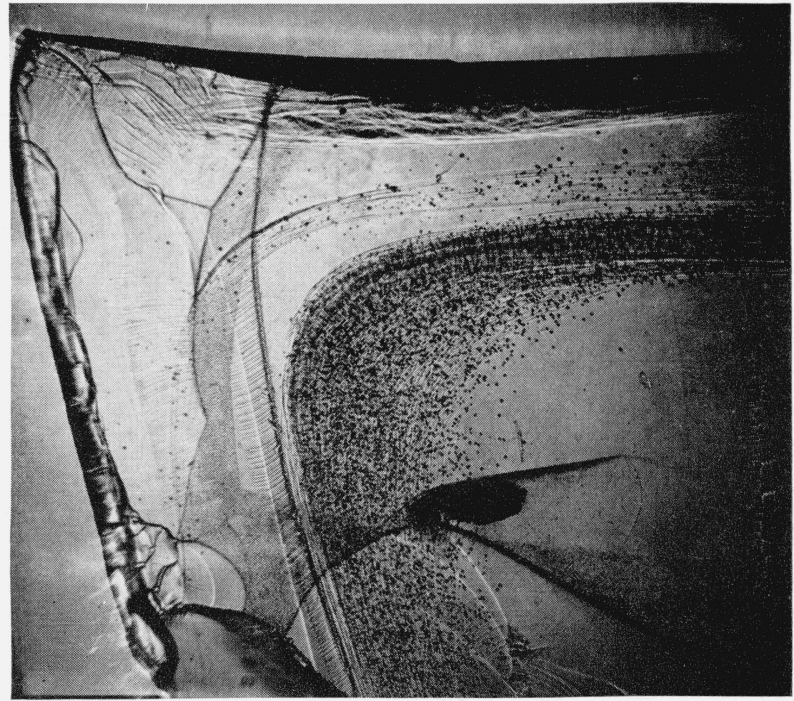

Figure 7. Sample from top left side of a melt showing a cloud of seeds associated with a heavy band of striae.

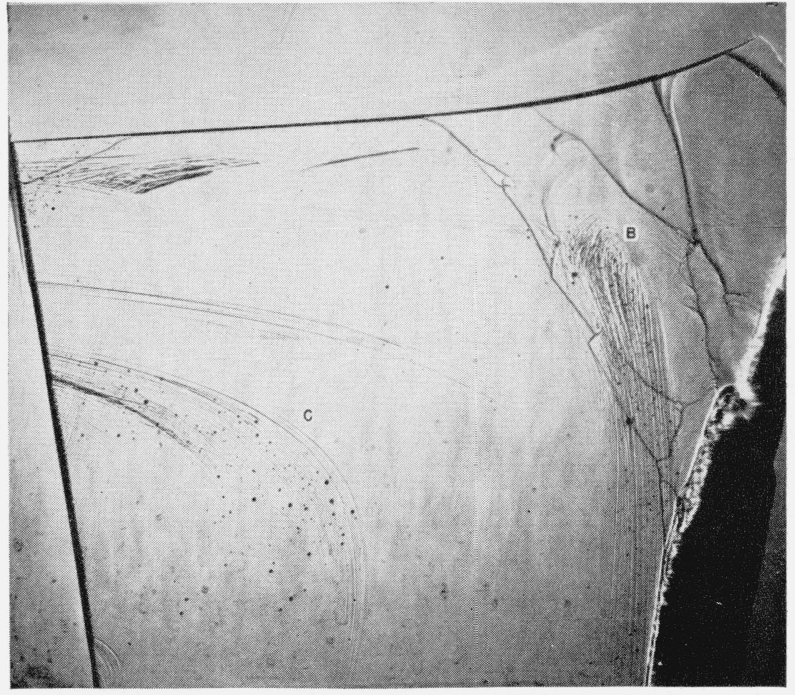

FiguRE 6. Sample from top right side of a melt shouing a band of striae $(C)$ curving downward into the melt, and a heavy band $(B)$, very close to the pot wall.

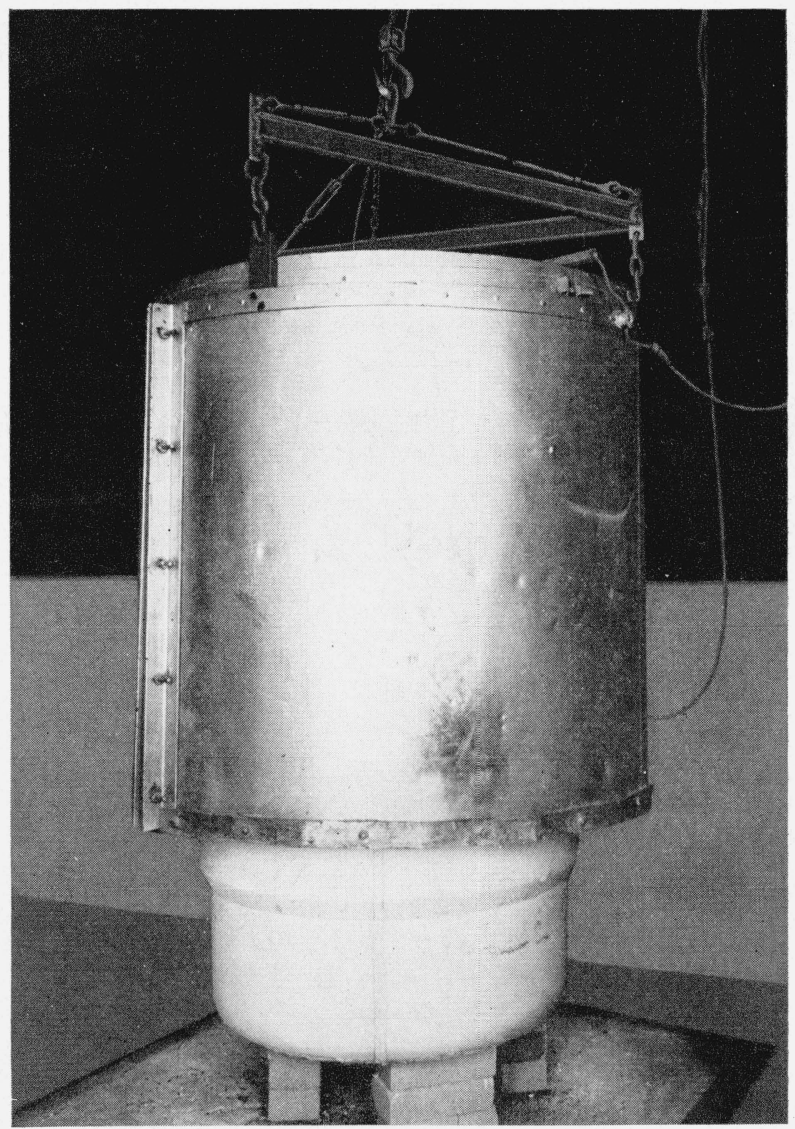

Figure 8. Cooling cover in suspended position over a pot of glass. 


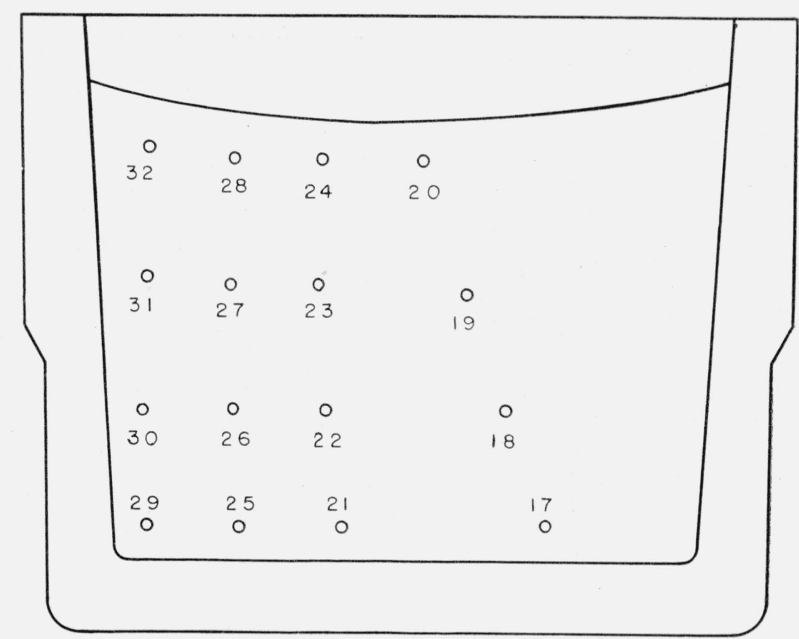

Figure 9. Position of thermocouples employed for the study of the temperature distribution in a pot of glass.

The numbers used here refer to the numbers on the recorder to which the thermocouples were connected.

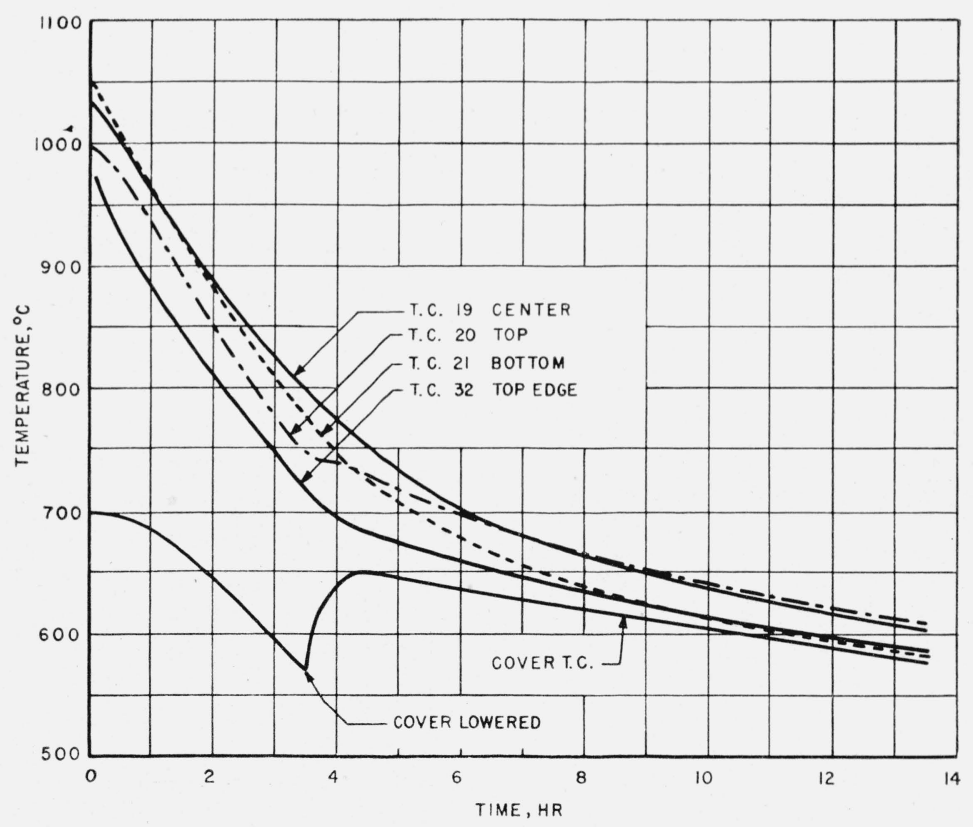

FIGURE 10. Time-temperature relations in various portions of the glass as shown by thermocouples 19, 20, 21, and 32. 

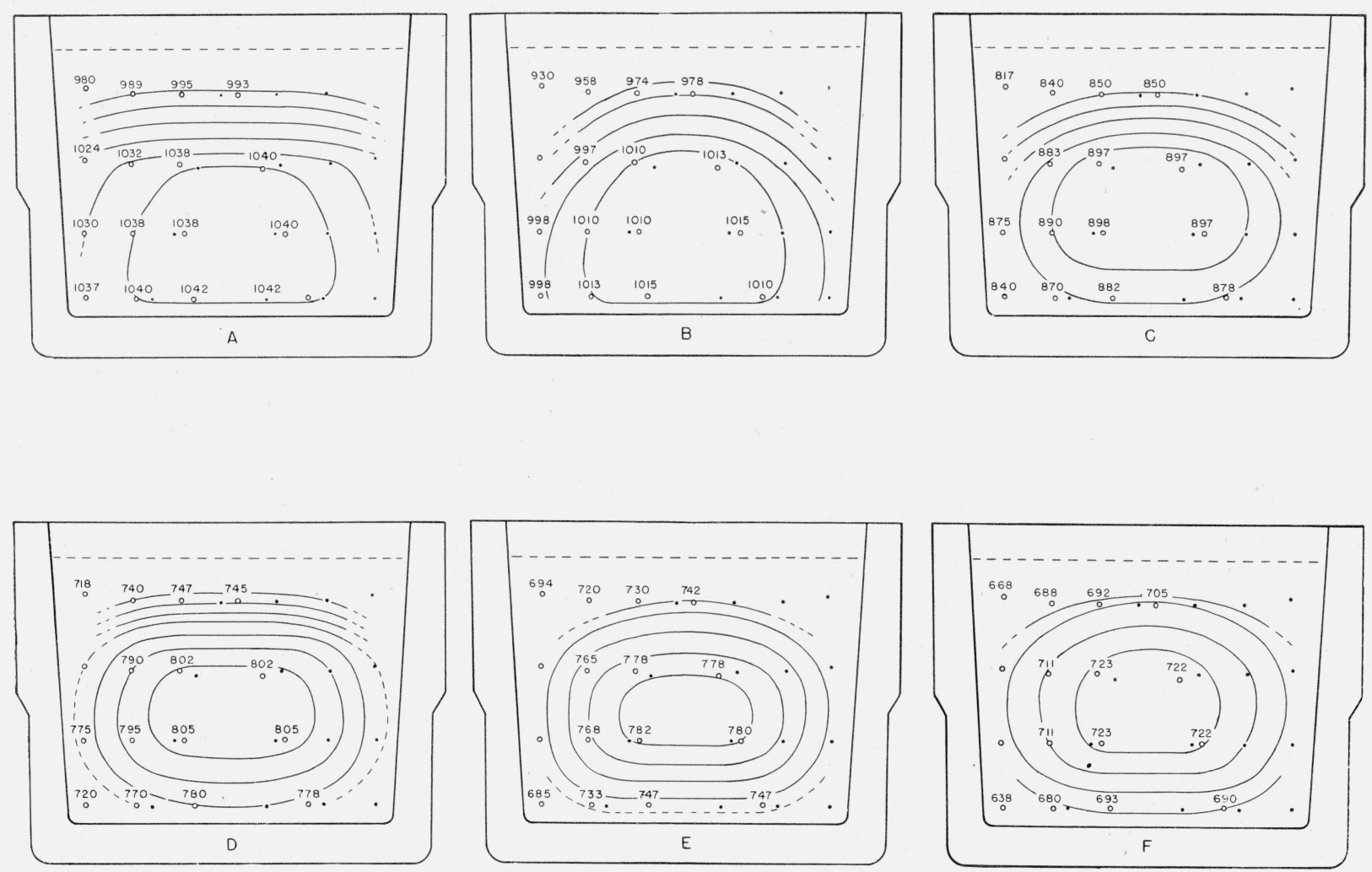

FigURe 11. Probable isotherms in a pot of glass during cooling.

a, $10 \mathrm{~min}$ after removal from the furnace; $\mathrm{b}, 1 / 2 \mathrm{hr}$ after removal from the furnace; c, $2 \mathrm{hrs}$ after removal from the furnace; $\mathrm{d}, 31 / 2 \mathrm{hrs}$ after removal from the furnace (the cooling cover was lowered to the floor at this time); e, $1 / 2 \mathrm{hr}$ after lowering cooling cover; $\mathrm{f}, 2 \mathrm{hrs}$ after lowering cooling cover.
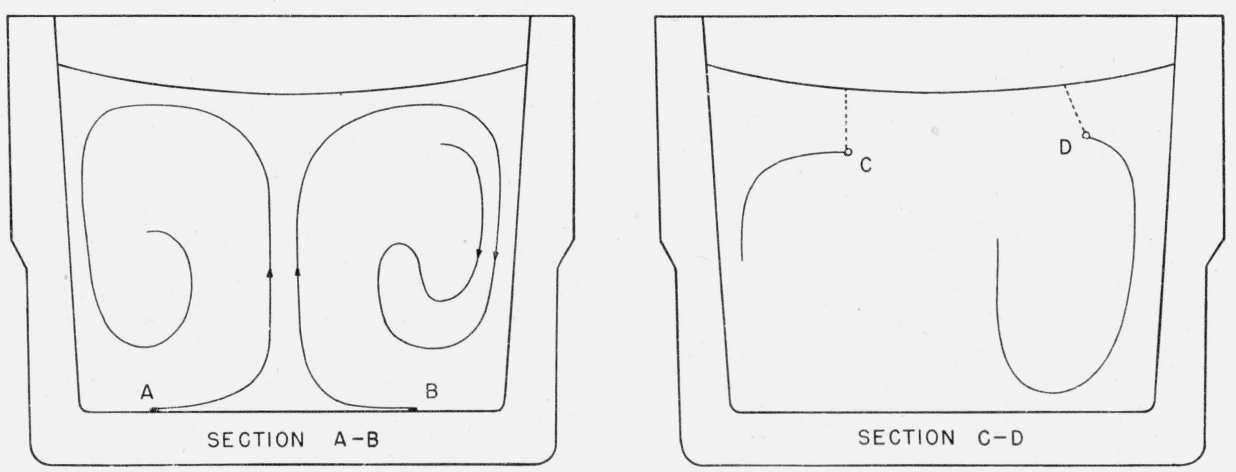

FIGURE 12. Final position of the copper-oxide tracers in melt 1. 
Figure 13. Copper-oxide tracers in melt 2 .

The portions" of the tracers deep in the glass show up as light streaks; those near the surface are dark.
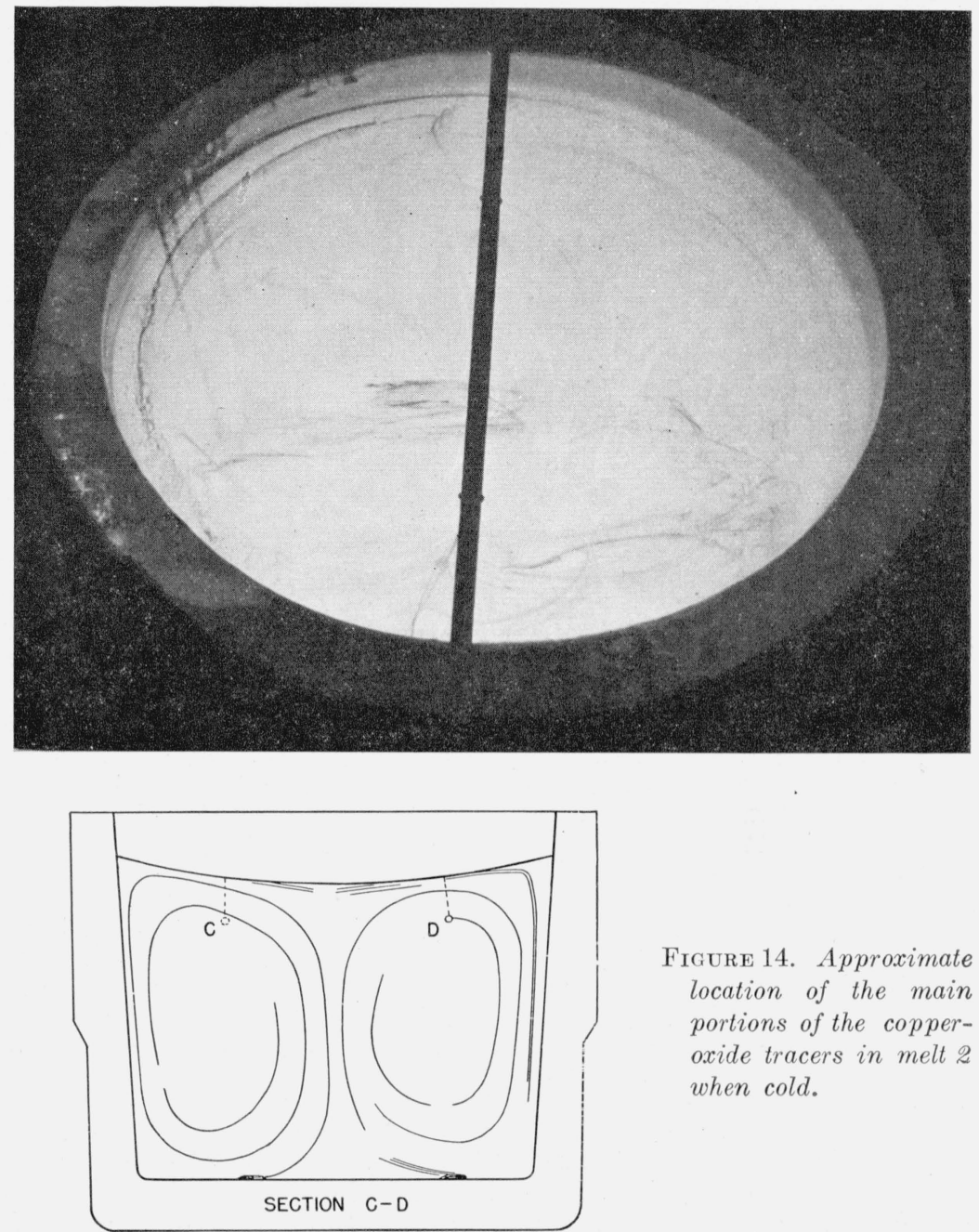

Figure 14. Approximate location of the main portions of the copperoxide tracers in melt 2 when cold.
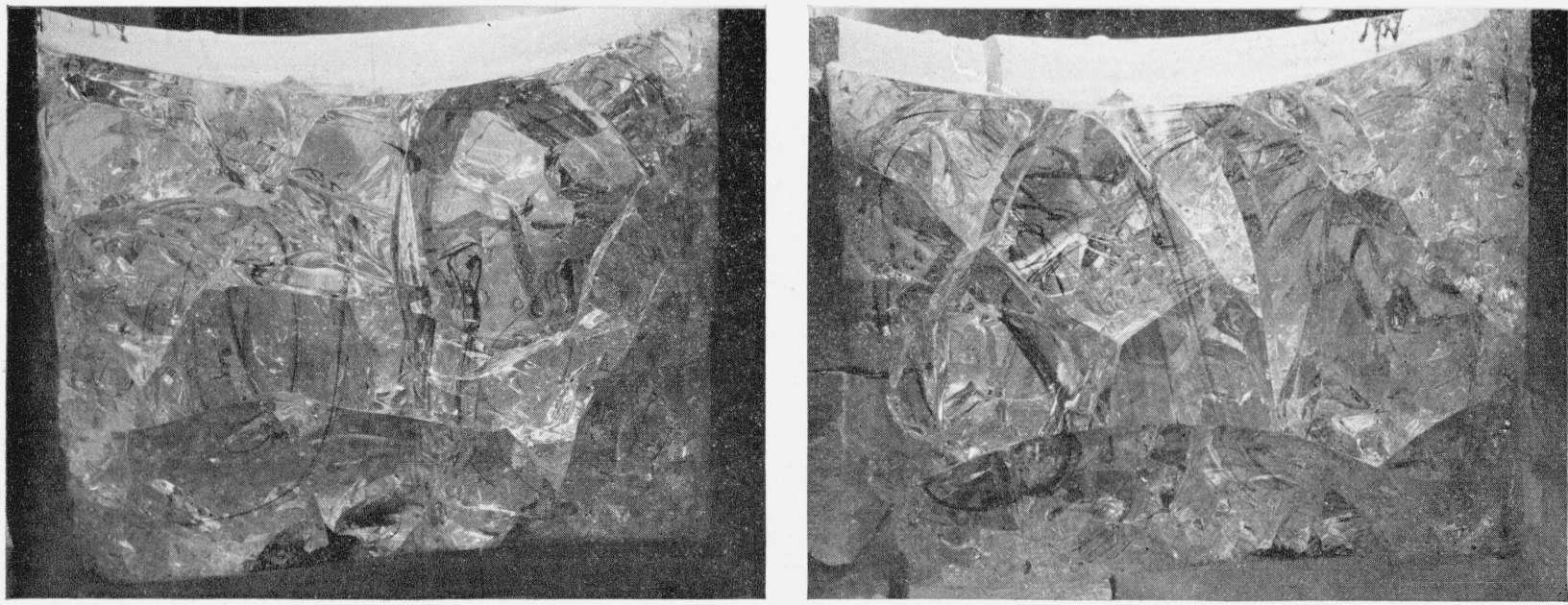

Figure 15. Melt 2 when opened for inspection.

The numerous streaks from the copper-oxide tracers and their tangled condition illustrate the excessive motion that occurred. 

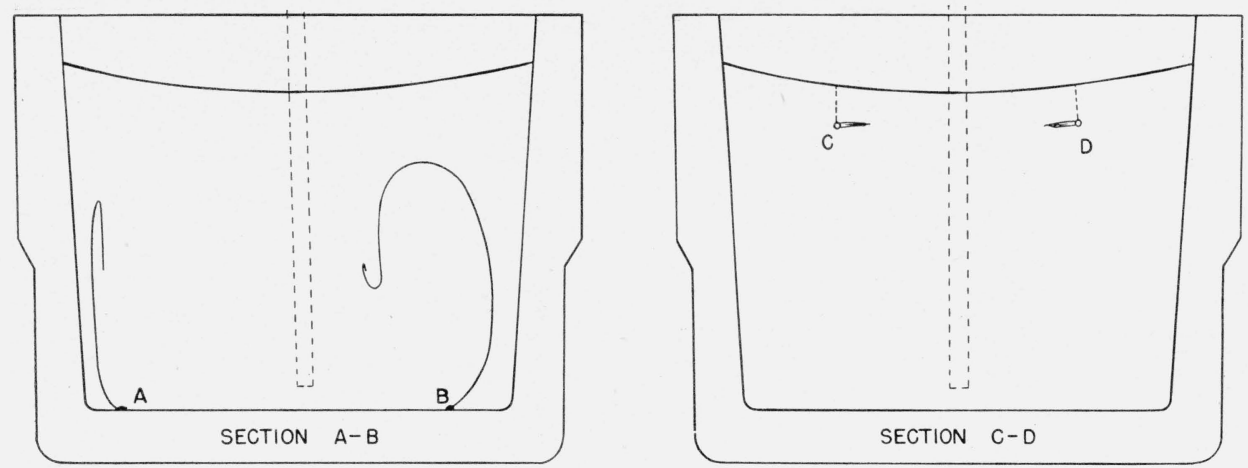

Figure 16. Final positions of the copper-oxide tracers in melt 3 with the water-cooled rod in the center.

The streak from $\mathrm{A}$ is similar to that from $B$, but is directed along the pot wall instead of toward the center of the pot.

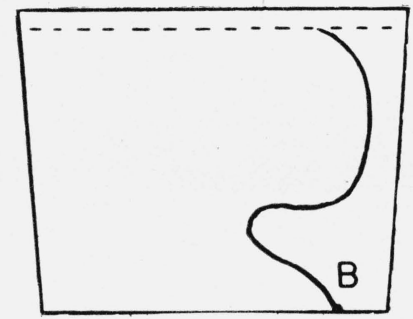

20 MIN

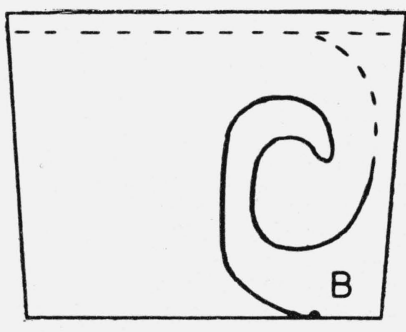

I HR

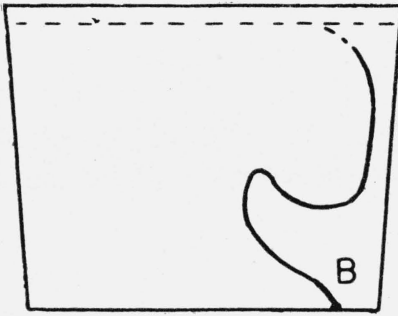

$30 \mathrm{MIN}$

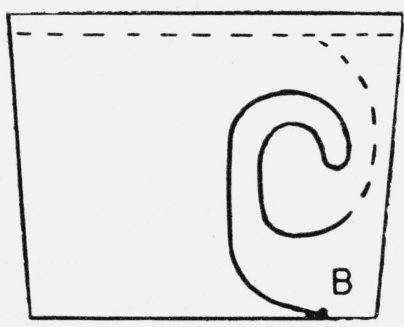

I HR 20 MIN

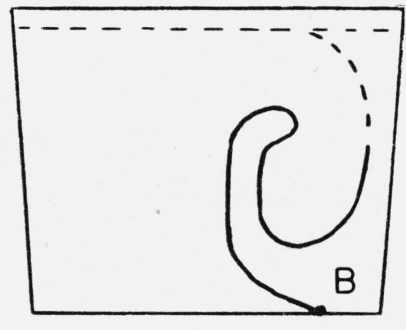

45 MIN

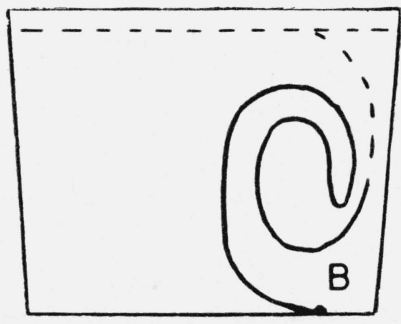

IHR 50 MIN

FIGURE 17. Sketches of tracer from ball $B$ drawn from observations of melt 4 during cooling, showing the formation of loops in the tracers.
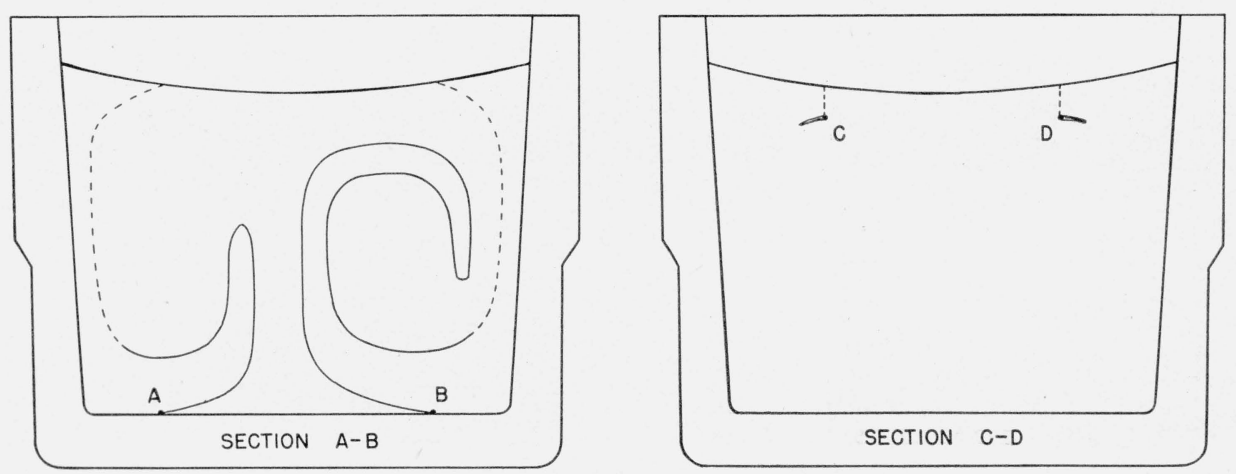

Figure 18. Final position of the copper-oxide tracers in melt 4 . 


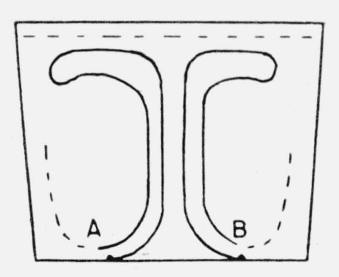

$45 \mathrm{M} \mid \mathrm{N}$

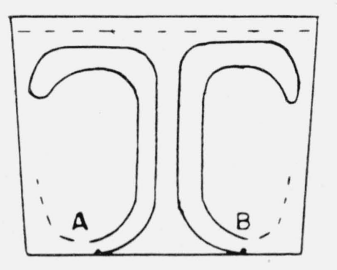

I HR I5 MIN

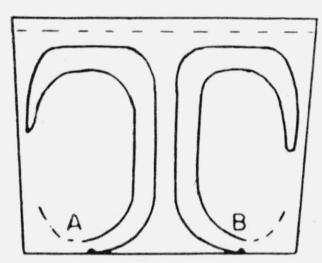

I HR $45 \mathrm{M}$ IN
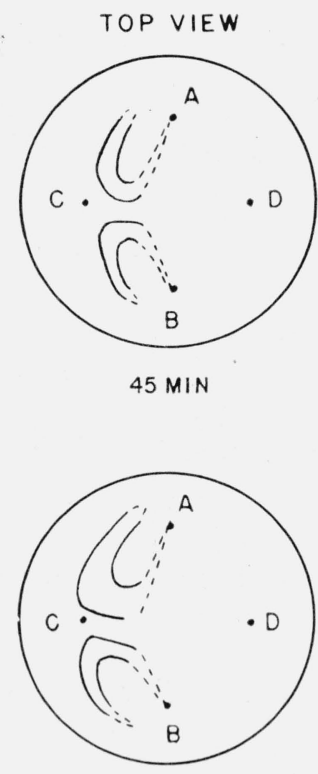

I HR I 5 MIN

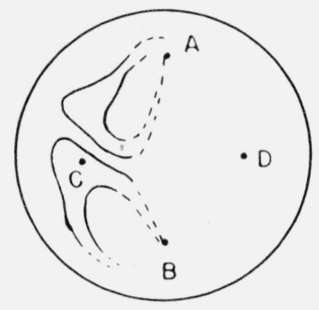

I HR 45 MIN

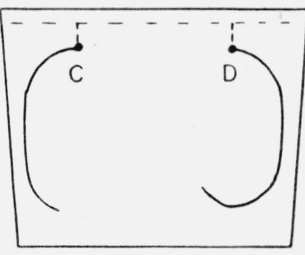

$45 \mathrm{MIN}$

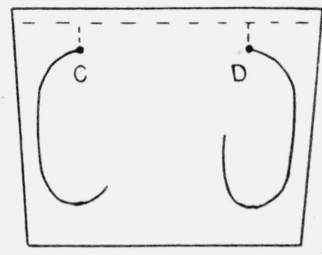

I HR I5 MIN

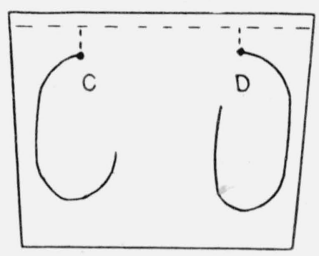

I HR 45 MIN

FIGURE 19. Sketches drawn from observations of the copper-oxide tracers in melt 5 during cooling.

The dotted portions shown in the top views represent those portions of the streamers across the bottom of the pot, and the ends of the loops going downward.
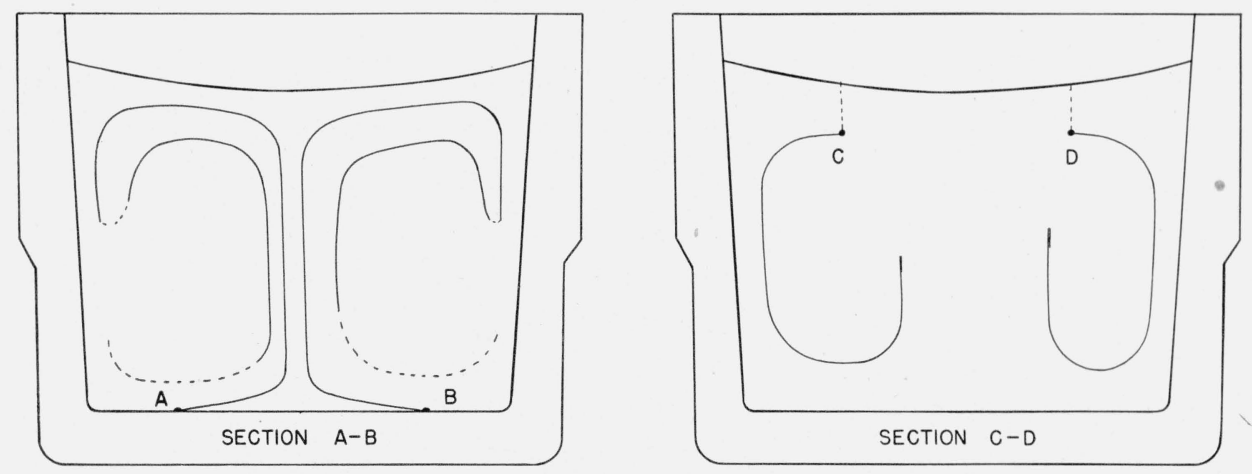

FIGURE 20. Final position of the copper-oxide tracers in melt 5. 

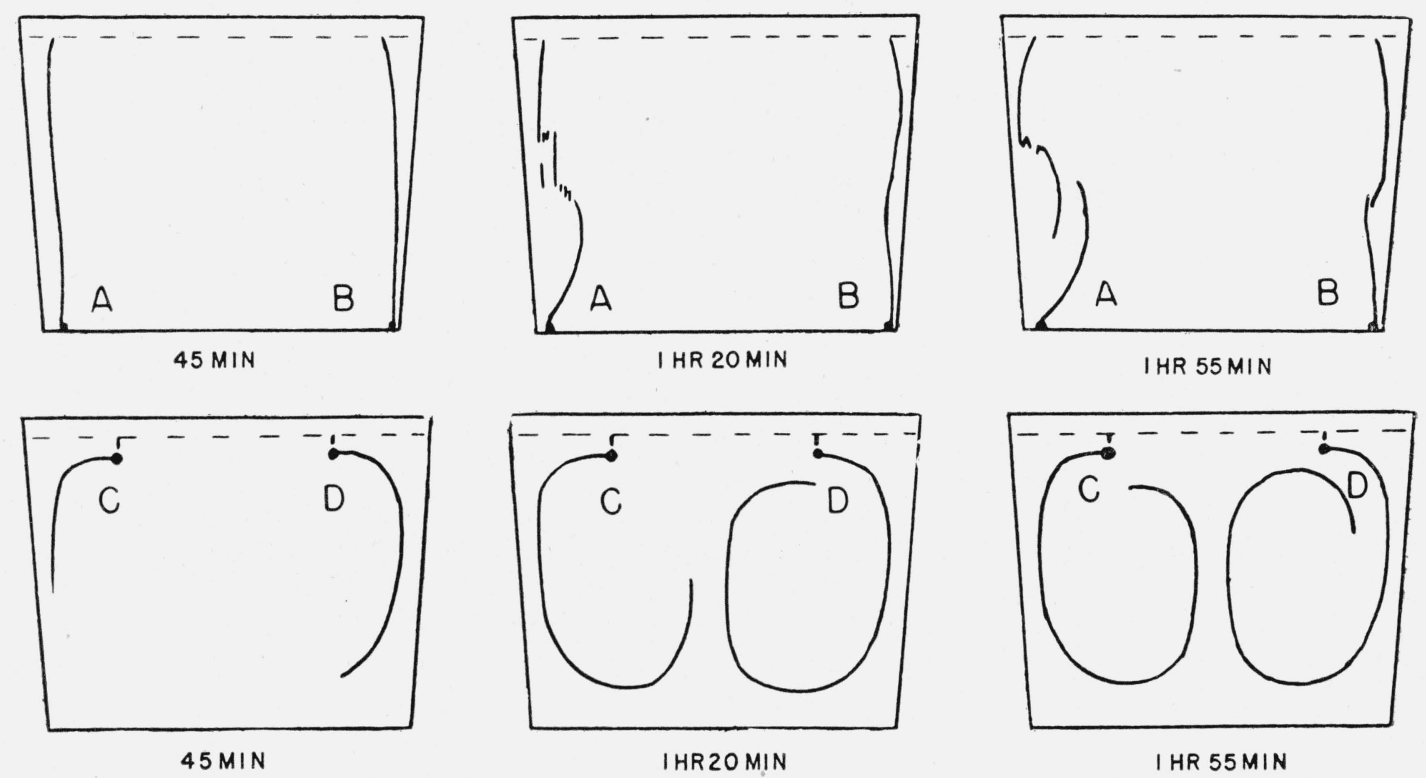

FIGURE 21. Sketches drawn from observation of the copper-oxide tracers in melt 6 during cooling.
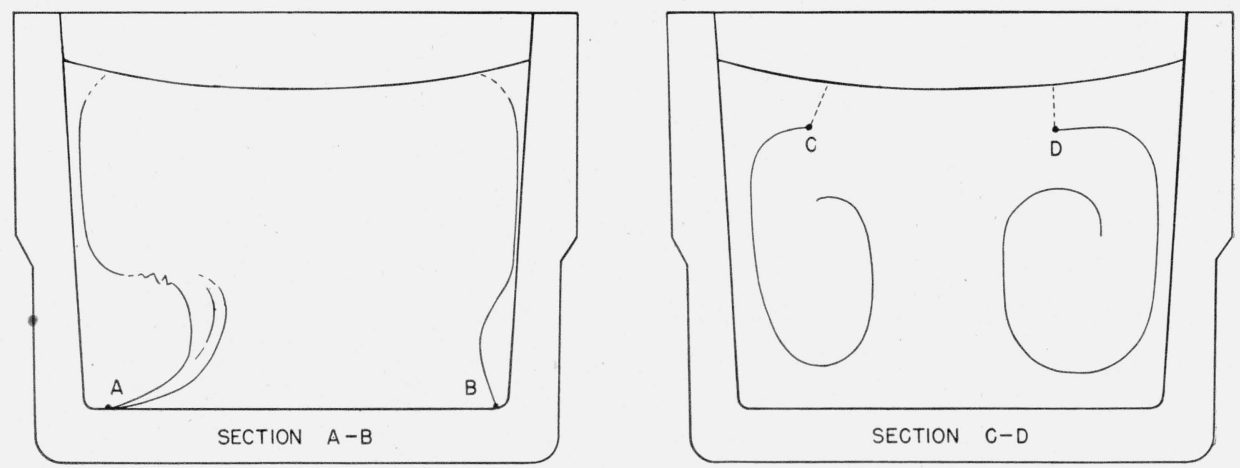

Figure 22. Final positions of the copper-oxide tracers in melt 6. 

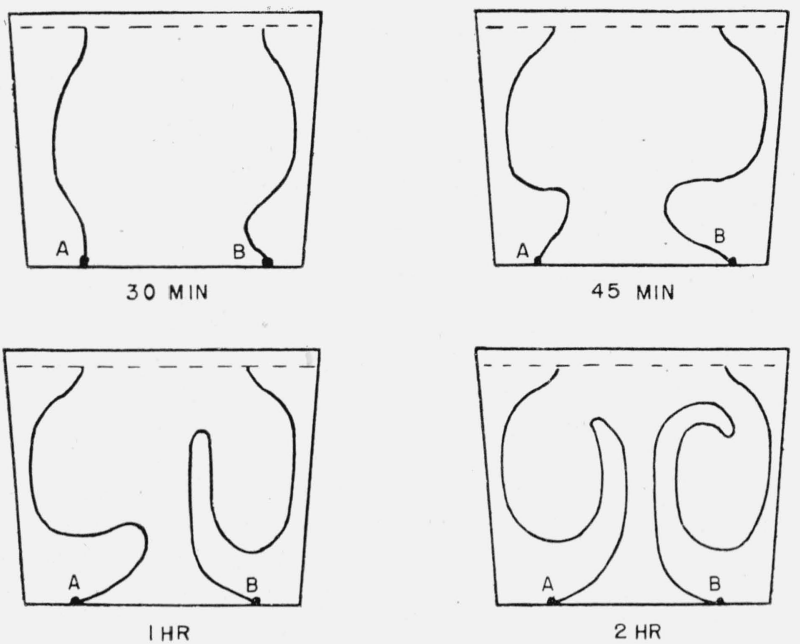

FIGURE 23. Sketches drawn from observations of melt 8 during cooling.
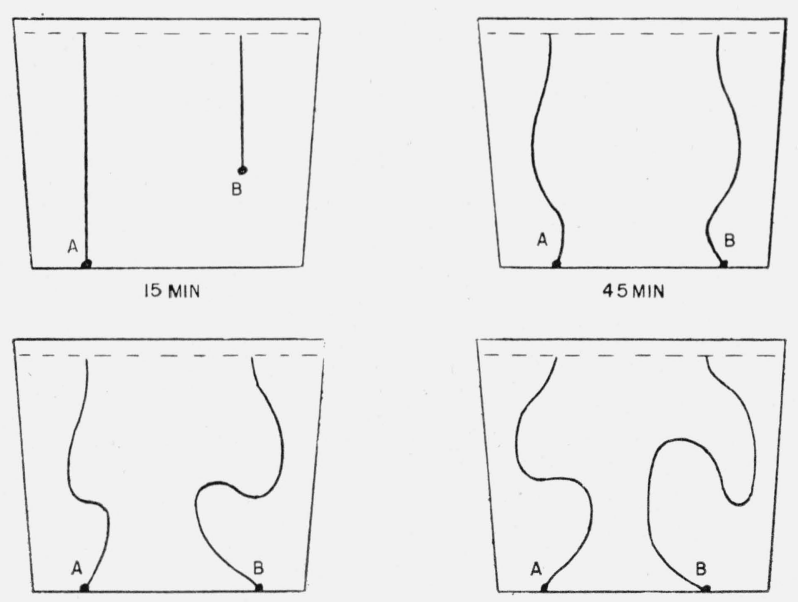

IHR 30 MIN

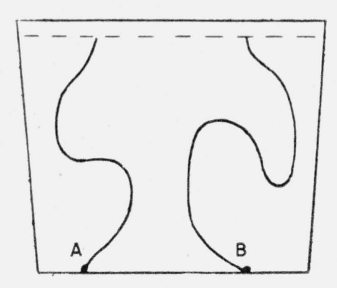

$2 \mathrm{HR}$

FIGURE 25. Sketches drawn from observation of melt 10 during cooling.

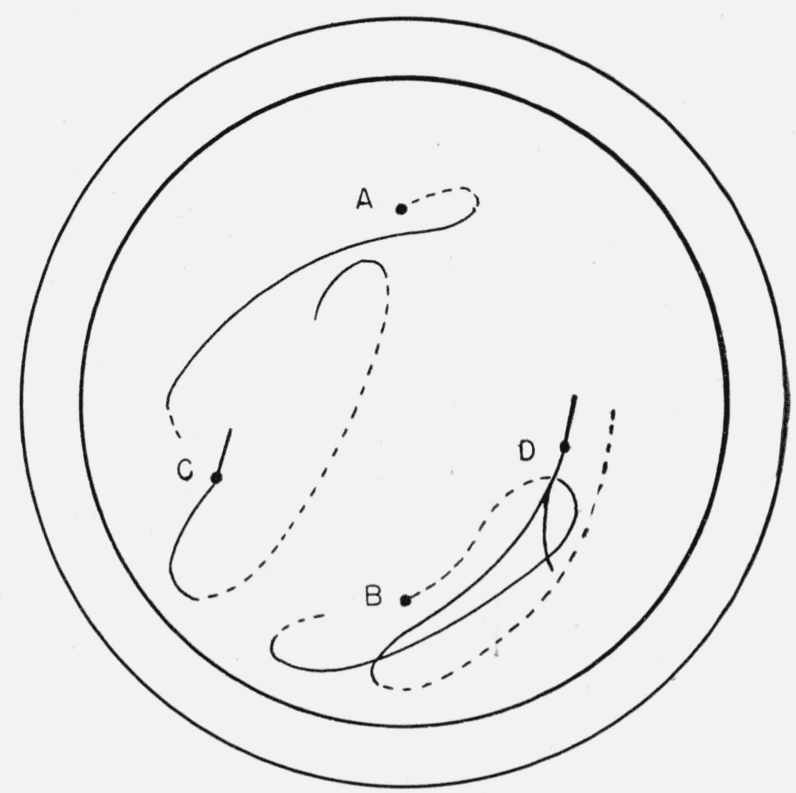

TOP VIEW

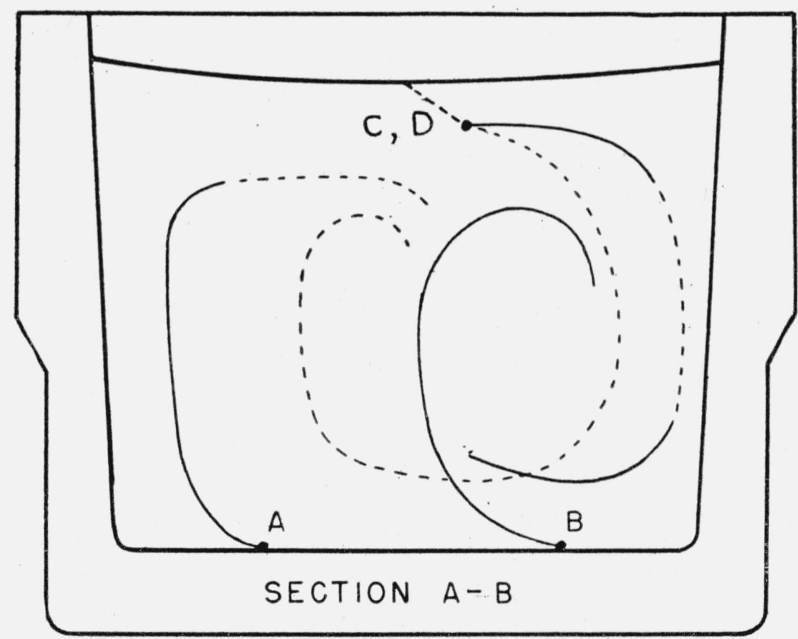

Figure 24. Position of the copper-oxide tracers in melt 9.

The top view represents the last observation made through the cover after all motion of the glass had ceased. The dotted lines indicate the portions of the tracers deep in the melt. Section A-B shows the final positions of the tracers in the cold melt. The solid lines show the portions of the tracers visible in the half of the pot containing ball $\mathrm{D}$, and looking toward $\mathrm{D}$. The dotted lines indicate portions of the tracers in the other half of the pot. 


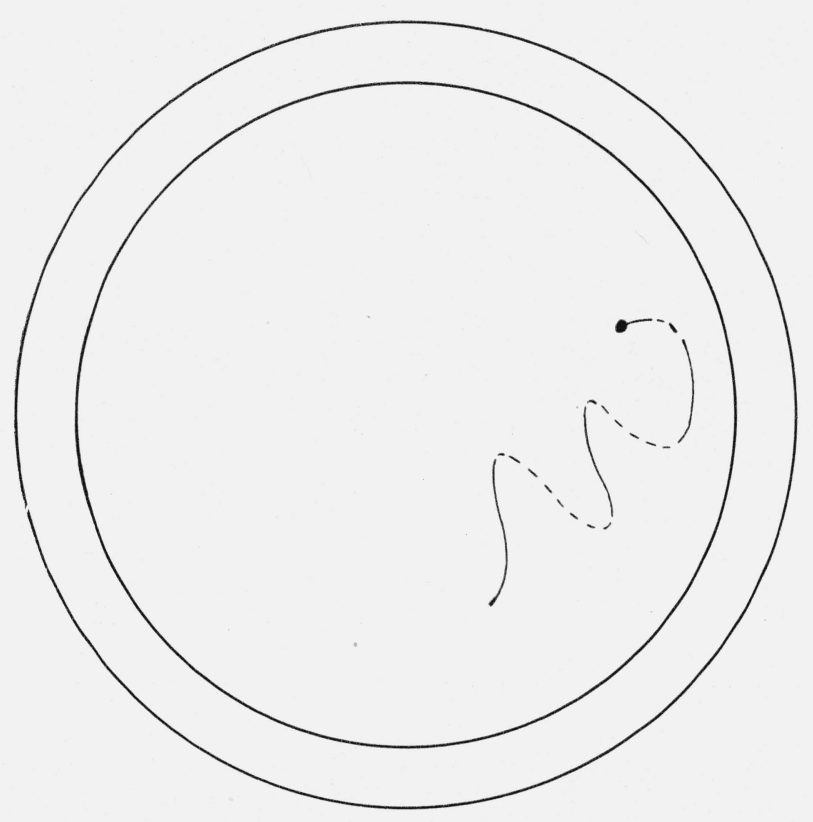

Figure 26. Top view of the copper-oxide tracer in melt 11.

The dotted lines indicate the lower portions of the spiral and the solid lines indicate the upper portions.

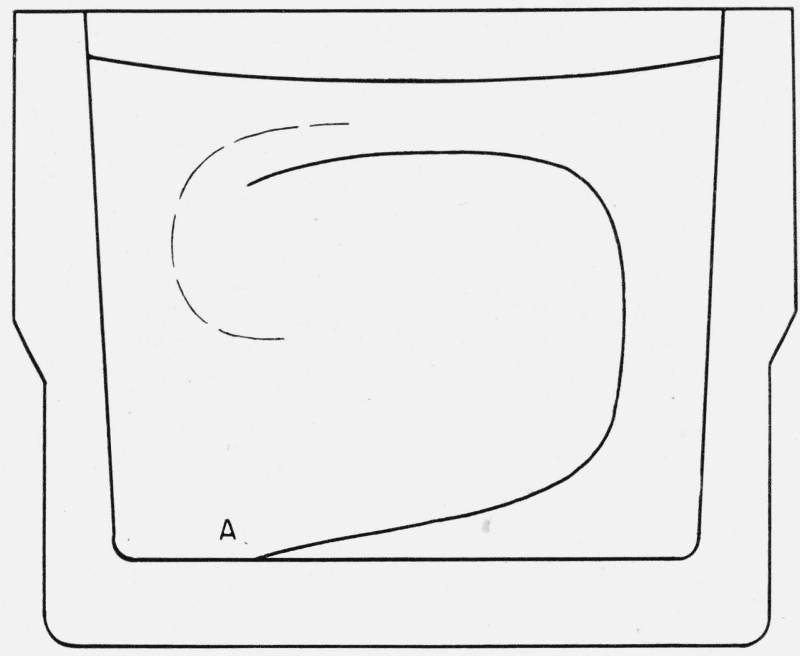

FIgURE 27. Final position of the copper-oxide tracer in melt 12.

The dotted lines indicate portions of the tracers in the other balf of the pot.

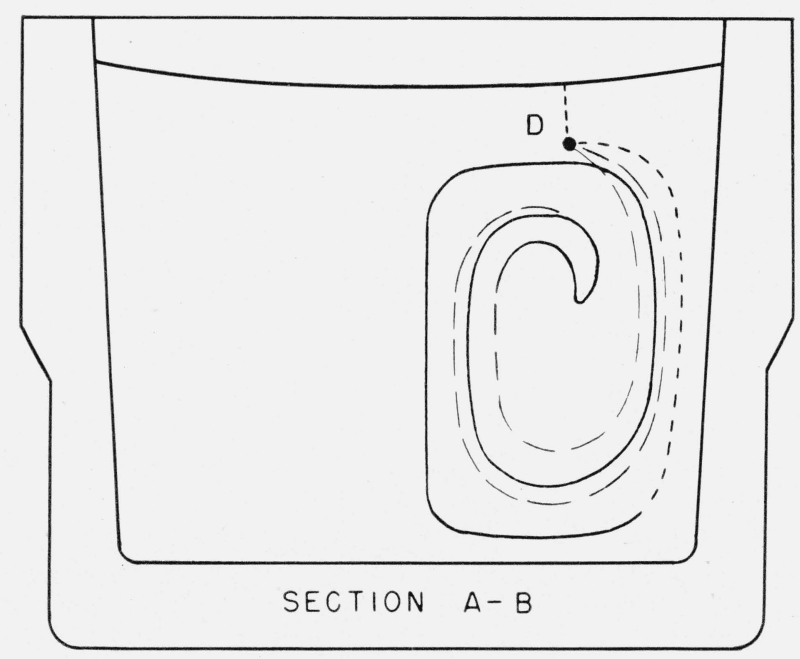

FIGURE 28. Final position of the copper-oxide tracer from ball $D$ in melt 13.

The dotted lines indicate portions of the tracers in the other half of the pot. 


\section{References}

[1] C. N. Fenner, The technique of making optical glass, J. Am. Ceram. Soc. 2, 102 (1919).

[2] H. S. Roberts, The cooling of optical glass melts, J. Am. Ceram. Soc. 2, 543 (1919).

[3] F. E. Wright, Manufacture of optical glass and of optical systems, Ordnance Department Document 2037, Government Printing Office, Washington 25, D. C.
[4] W. H. Parsons and Herbert Insley, Attack on refractory clay pots by optical glass, J. Research NBS $\mathbf{3 6}$, 31 (1946) RP1689.

[5] Francis W. Glaze and Clarence H. Hahner, Optical glass at the National Bureau of Standards, NBS Circular 469 (1948); Glass Ind. 29, 562 (1948).

[6] Hans Jebsen-Marwedel, Glastechnische Fabrikationsfehler (Julius Springer, Berlin, 1936).

Washington, October 26, 1948. 